\title{
Sistemas de fotoativação e seus impactos nas restaurações em resina composta: uma revisão de literatura
}

\author{
Photoactivation systems and their \\ impacts on resources in compound resin: \\ a literature review
}

\section{Raquel Sampaio Boaventura1 (D) Mariana Almeida Basílio² (iD}

\begin{abstract}
1'Autora para correspondência. Escola Bahiana de Medicina e Saúde Pública (Salvador). Bahia, Brasil. raquel_boaventura@hotmail.com
\end{abstract} ${ }^{2}$ Escola Bahiana de Medicina e Saúde Pública (Salvador). Bahia, Brasil. mariana_basilio@yahoo.com.br

\begin{abstract}
RESUMO | As substâncias fotoiniciadoras e os aparelhos de fotoativação estão diretamente ligados ao desempenho físico-mecânico e químico das resinas compostas. Devido à coloração amarelada proveniente da canforoquinona (CQ), os fotoiniciadores alternativos têm sido usados de forma complementar ou substituta. Assim, o objetivo do presente estudo foi desenvolver uma revisão da literatura sobre os fotoiniciadores em correlação com a fotoativação e seus impactos nas restaurações em resina composta. A revisão da literatura foi conduzida a partir de buscas nas bases de dados Scielo, PubMed e Google Acadêmico através dos descritores: resinas compostas, polimerização e fotoiniciadores. Na busca realizada no período entre março e junho de 2020, dos 42 artigos encontrados, 37 artigos foram utilizados. Dentre as variações dos sistemas fotoiniciadores, observou-se que, no geral, elas apresentaram pontos positivos, como bom desempenho físico-mecânico e químico, com a avaliação do grau de conversão, resistência flexural e microdureza. Assim como apresentaram também pontos negativos como alta toxicidade, formações de gaps e índices insatisfatórios de microinfiltração em dentina. Em relação aos sistemas de fotoativação, os diodos emissores de luz (LEDs), chamados de polywave trouxeram vantagens por possuírem alta irradiância, alto grau de colimação do feixe luminoso, e emitirem um espectro de onda maior, que atinge a cor violeta, necessária para ativar a reação química de polimerização dos fotoiniciadores alternativos. Pode-se concluir que o surgimento das novas substâncias fotoiniciadoras e os aparelhos polywave estabelecem certa harmonia com a capacidade de fornecimento de luz, a reação das substâncias e o alcance das propriedades físico-mecânicas fornecidas por elas.
\end{abstract}

PALAVRAS-CHAVE: Resinas compostas. Polimerização. Fotoiniciadores.
ABSTRACT | Photoinitiating substances and photoactivation devices are directly connected to the physical-mechanical and chemical performance of the composite resins. Due to the yellowish coloration from camphorquinone (CQ), alternative photoinitiators have been used in a complementary or substitute way. Thus, the study aimed to develop a literature review on photoinitiators in correlation with photoactivation and its impacts on composite resin restorations. The literature review has been conducted based on researches in the Scielo, PubMed, and Google Scholar databases through the descriptors: composite resins, polymerization, and photoinitiators. In the search carried out between March and June 2020, of the forty-two articles found, thirty-seven articles were used. Among the variations of the photoinitiator systems, it has been observed that, in general, they presented positive points such as good physical-mechanical and chemical performance with the evaluation of the degree of conversion, flexural strength, and microhardness. They also presented negative points, such as high toxicity, gap formation, and unsatisfactory microleakage indices in dentin. Concerning photoactivation systems, light-emitting diodes (LEDs), called polywave, brought advantages by emitting a larger wave spectrum that reaches the violet color, necessary to activate the polymerization chemical reaction of the alternative photoinitiators. It can be concluded that the emergence of new photoinitiating substances and polywave devices establish a certain harmony with the light supply capacity, the reaction of the substances, and the reach of the physical-mechanical properties provided by them.

KEYWORDS: Composite resins. Polymerization. Photoinitiators. 


\section{Introdução}

Para atender às demandas estéticas e funcionais exigidas, os materiais restauradores sofreram diversas modificações ao longo do tempo, na sua composição e estrutura, a fim de alcançar melhores performances clínicas 1 . O principal objetivo dos estudos relacionados aos compósitos tem sido a criação de um material universal que apresente resultados satisfatórios quando empregado tanto em dentes anteriores quanto nos posteriores, atendendo aos requisitos de boa adesão, preservação da estrutura dental sadia e capacidade de reprodução do natural .

As resinas compostas possuem três componentes principais, o primeiro deles é a matriz resinosa ou orgânica que se une às partículas de carga. Essas partículas de carga podem ser chamadas também de partículas inorgânicas ou de preenchimento, e representam o segundo componente. O terceiro é o agente de união silano, que promove a união química entre as cargas inorgânicas e a matriz resinosa ${ }^{2,3}$.

A matriz orgânica das resinas compostas é formada por moléculas pequenas, chamadas de monômeros substâncias, que sofrem união química e formam longas cadeias chamadas de polímeros, conceituando o processo de polimerização 4,5 . Para que tal processo seja realizado de forma eficiente nas resinas fotoativadas, são necessários compostos químicos responsáveis por desencadeá-lo: os sistemas fotoiniciadores ${ }^{5}$.

Quanto às substâncias fotoiniciadoras, como o nome sugere, elas são sensíveis à luz e podem ser chamadas também de fotossensibilizantes. A mais comumente utilizada nas resinas compostas é a canforoquinona (CQ), uma alfa-dicetona que absorve luz com comprimento de onda entre 460-480 nanômetros $(\mathrm{nm})$. O aumento da concentração desse fotoiniciador leva a maior grau de conversão dos monômeros, influenciando diretamente nas propriedades mecânicas e biológicas dos materiais ${ }^{5-8}$. Entretanto, sua cor amarelada faz com que a canforoquinona se torne de difícil incorporação por sua interferência na coloração das resinas mais claras ou que exigem alto grau de translucidez, pois ao dificultar a ação da luz no incremento da resina composta por completo, não permite que aconteça o efeito "photobleaching" ou de fotobranqueamento de forma satisfatória ${ }^{5,7,8}$.
Tal efeito consiste na quebra do cromóforo após receber a irradiação luminosa e na perda da coloração amarelada após a polimerização ${ }^{5}$. Por conta disso, algumas substâncias fotoiniciadoras estão sendo utilizadas como alternativa em substituição ou de forma complementar da CQ? .

Dentre os sistemas fotoiniciadores usados, pode-se destacar o 1-fenil-1;2-propanodiona (PPD), o óxido mono-acil fosfínico (MAPO ou Lucerim TPO), o óxido bisacilfosfínico (BAPO ou Irgacure 819), o hexafluorofosfato de difeniliodônio (DPIHFP), o 1,3-benzodioxole (BDO), álcool piperonílico (AP), o 1,3-dietil-2-tiobarbitúrico (TBA) $(5,9)$ e o Sistema APS (Advanced Polymerization System), que possui poucos dados disponíveis sobre ele na literatura. Tais substâncias possuem pico de absorção de luz abaixo da $\mathrm{CQ}$, mas estão dentro do espectro útil da faixa de luz visível emitidas pelos aparelhos de LED que emitem luz com comprimentos de onda na faixa do azul e do violeta ${ }^{5}$.

Após a reação de polimerização, a porcentagem de monômeros transformados em polímeros é chamada de grau de conversão. Esse aspecto físico-químico é um dos fatores contribuintes para que os compósitos ofereçam melhores propriedades mecânicas. Para tanto, é necessário que o grau de conversão seja o mais alto possível e forme o maior número de ligações cruzadas, já que o mesmo reflete a eficácia da polimerização $0^{4,7}$. Alguns aspectos estão diretamente ligados a variação da taxa do grau de conversão, como tipo do fotoiniciador presente no compósito, a quantidade de energia emitida sobre o material, a natureza e a qualidade da luz usada, o grau de colimação dessa luz, o tempo, a distância, a angulação e a centralização da fonte de luz em relação ao material a ser polimerizado, a homogeneidade do facho de luz emitido, além das interferências comportamentais do operador ${ }^{10,11}$.

Assim como os aparelhos fotoativadores, os materiais restauradores também sofreram adaptações e mudanças com o objetivo de melhorar o desempenho mecânico e a longevidade das restaurações. Uma resina composta com falhas na polimerização sofre alto grau de degradação da matriz orgânica e, consequentemente, perda do seu desempenho mecânico e biológico, além de apresentar diminuição da biocompatibilidade ${ }^{5,6}$. Por isso, torna-se necessário o aprofundamento do estudo das técnicas e materiais 
empregados nos procedimentos restauradores, a fim de reduzir a taxa de insucesso e elevar a qualidade e longevidade das restaurações. Por fim, o presente estudo tem como objetivo rever a literatura sobre os fotoiniciadores em correlação com a fotoativação e seus impactos nas restaurações em resina composta.

\section{Metodologia}

A presente revisão de literatura foi construída a partir de artigos científicos, nos idiomas português e inglês, publicados em periódicos nacionais e internacionais através de ferramentas de busca como Scielo, PubMed, Google Acadêmico, além de consulta bibliográfica. Os descritores utilizados para a pesquisa foram resinas compostas (composite resin), polimerização (polymerization) e fotiniciadores (photoinitiators). Os artigos foram pré-selecionados a partir da leitura e análise dos títulos e respectivos resumos. Como critério de elegibilidade foram pré-selecionadas 42 publicações entre os anos de 2015 e 2020, que possuíam como abordagem principal o comportamento das resinas compostas frente aos diferentes métodos de polimerização e como a variação dos seus fotoiniciadores influencia no desempenho físico-mecânico dos procedimentos restauradores. Artigos publicados em anos anteriores a 2015 foram mantidos por conta da relevância apresentada nos seus conteúdos. Após a leitura das referências pré-selecionadas com base nos critérios de inclusão estabelecidos, 37 publicações foram utilizadas.

\section{Revisão de literatura}

Antes do surgimento das resinas compostas, a Odontologia enfrentou difíceis desafios no emprego das restaurações diretas, principalmente em dentes anteriores. Materiais de presa química que se apresentavam em sistemas pasta-pasta ou pó-líquido, como o cimento de silicato e as resinas acrílicas, eram os únicos disponíveis para tais procedimentos. Entretanto, o cimento possuía alta solubilidade e baixo desempenho mecânico, enquanto as resinas acrílicas apresentavam alta contração de polimerização, altos índices de infiltração marginal, difícil controle do tempo de trabalho, tendência à impregnação por corantes e resultado estético inadequado. Como forma de solucionar tais problemas, esse sistema cedeu lugar para as resinas ativadas por polimerização física: a luz $4,5,12$.

A partir da década de 70, o emprego de resinas compostas de polimerização física por meio de fotoativação pela luz ultravioleta mudou os caminhos da odontologia restauradoraz, ,13. Porém, há algum tempo, a luz ultravioleta encontra-se em desuso para fins odontológicos por conta dos efeitos nocivos da radiação para pacientes e operadores, tais como queimaduras de córnea e catarata. Além disso, as lâmpadas possuem vida útil curta e não atuam bem em profundidade no material ${ }^{7,13}$. Devido às desvantagens de tal método, a fotoativação por luz ultravioleta foi subtituída por fontes de luz visível por volta do ano de 1976, as quais vêm sendo aprimoradas para uso na polimerização de materiais resinosos ${ }^{14,15}$.

A luz visível é composta por ondas que correspondem a faixa de comprimento entre 400 e $700 \mathrm{~nm}$. Com o advento e emprego da tecnologia Light-Emitting Diode (LED) em vários segmentos, essa fonte de luz começou a ser usada também na Odontologia, visando melhorar o grau de polimerização dos materais resinosos e a qualidade das restaurações. Dentre as diversas fontes existentes, a LED é a mais utilizada na Odontologia restauradora contemporânea por conta de vantagens, como pureza da luz produzida, emissão de comprimento de onda especificamente na faixa de luz azul ou violeta, ausência ou geração mínima de calor, maior vida útil, além de serem aparelhos portáteis e silenciosos. Os LED's das primeiras gerações produzem energia luminosa na faixa de comprimento entre 400 e $500 \mathrm{~nm}$, suficientes para excitar o fotoiniciador presente nos materiais resinosos atuais e desencadear a reação de polimerização ${ }^{\text {11.14. }}$.

Em associação com a evolução das unidades de luz utilizadas no processo de fotoativação, as resinas compostas também foram desenvolvidas ao longo dos anos e aliadas aos aparelhos fotoativadores, aumentaram a qualidade das restaurações. A maior modificação nos compósitos aconteceu em 1956 quando Bowen ${ }^{16}$ introduziu o Bisfenol A Glicidil metacrilato (Bis-GMA) como monômero base da matriz resinosa ${ }^{12,14}$, fato que alterou significativamente o comportamento físico e mecânico dos materiais restauradores. Outro componente testado ao longos dos anos foi a canforoquinona (CQ), fotoiniciador que, associado a um co-iniciador, exerce o papel de desencadear o processo de transformação de monômeros em polímeros ${ }^{14}$. 
Schneider et al. ${ }^{12}$ relataram que as propriedades mecânicas dos compósitos resinosos são determinadas, quanto à composição, pela matriz orgânica composta pelos monômeros, que se transformarão em polímeros, pela carga inorgânica e pelo agente de união ${ }^{12}$. A disposição desses componentes vai determinar a microdureza, propriedade importante do material. A dureza de um material foi definida por Souza et al. $\frac{13}{}$, como "a medida relativa de sua resistência à penetração quando uma carga específica constante é aplicada". Sendo diretamente proporcional à resistência ao desgaste e à resistência mecânica do material ${ }^{13}$, quando a microdureza do material é afetada, ele pode apresentar dissolução da matriz orgânica e exposição das partículas de carga, resultando no aumento da rugosidade da sua superfície, processo que o torna mais vulnerável à pigmentação externa, favorece o acúmulo de placa e influi diretamente no desempenho clínico e mecânico, assim como na longevidade da restauração ${ }^{12,17}$.

Almeida et al.? afirmam que a intensidade da luz, a composição do material e a concentração as substâncias fotoiniciadoras contidas nas resinas compostas estão diretamente ligadas ao desempenho mecânico das restaurações devido ao grau de conversão do material após a reação de polimerização? O grau de conversão foi definido como a porcentagem de monômeros transformados em polímeros s, $^{4}$. Portanto, quanto maior este índice, melhor polimerizado estará o material restaurador, melhores serão suas propriedades mecânicas e maior o sucesso a longo prazo 5,11 .

Por outro lado, a polimerização inadequada ou subpolimerização está relacionada a propriedades mecânicas inferiores, resultando em abrasão aumentada, maior índice de fratura e até mesmo sensibilidade pulpar ${ }^{18}$. A liberação dos monômeros não polimerizados pode ser direcionada à polpa por meio dos túbulos dentinários e provocar reações inflamatórias no tecido. Consequentemente, a degradação do material na cavidade bucal está relacionada com sensibilidade pós-operatória, maior descoloração, aumento dos defeitos marginais, maior descolamento, e mais acometimento por cáries recorrentes $5,711,19,20$.
Os índices de grau de conversão e a profundidade de cura das resinas compostas restauradoras têm sido correlacionados a fatores como composição do material, cor e translucidez, distância e potência da fonte de luz, espessura da camada de material e tempo de irradiação. O nível ideal desse grau seria uma total conversão das moléculas de monômeros da matriz resinosa em polímeros durante a reação de polimerização. Ele pode ser utilizado também como método para determinar a eficiência do fotoiniciador empregado na resina composta ${ }^{5}$. Por conta disso, é um fator extremamente relevante a ser abordado quando é avaliado o desempenho mecânico, aspectos físicos, químicos e sucesso a longo prazo das restaurações feitas com resinas compostas ${ }^{\mathrm{Z}, 11,13}$.

\section{Sistemas fotoiniciadores nos materiais resinosos}

Tratando sobre a influência dos fotoiniciadores nas propriedades mecânicas de uma resina composta, é possível perceber que apesar de tais substâncias corresponderem a uma pequena porção da matriz resinosa, elas possuem certa relevância neste aspecto. Por conta disso, ao longo do tempo, pesquisas se basearam em diversificar a composição ou a taxa de concentração dos fotoiniciadores, e o próprio sistema de fotoativação para polimerização, com a intenção de estabelecer níveis ideais com o mínimo de desvantagens possível ${ }^{19}$.

As substâncias fotoiniciadoras são divididas em dois grupos. As do Tipo I e as do Tipo II. As do Tipo I liberam radicais livres após a absorção de luz e consequente fracionamento da sua molécula, enquanto as do Tipo II necessitam da integração com uma segunda substância que se comporta como doadora de hidrogênio, chamada de co-iniciadora, para liberar os radicais após a absorção da luz ${ }^{5}$.

A canforoquinona (CQ), alfa di-cetona comumente incorporada às resinas compostas como fotoiniciador, é categorizada como uma substância do tipo II, ou seja, necessita do co-iniciador, que na maioria dos materiais é a amina terciária, chamada de 4-dimetilamino benzoato de etila (EDAB), responsável por desempenhar o papel de agente redutor, doador de hidrogênio, para a liberação de radicais livres ser eficiente durante a polimerização do material ${ }^{5,9}$. 
A CQ, atualmente, é o fotoiniciador mais utilizado em compósitos restauradores, absorve luz no comprimento de onda entre 430 e $510 \mathrm{~nm}$, faixa correspondente a região azul dos espectros de luz visível. Nisso consiste a vantagem determinante da CQ, pois seus espectros de absorção de luz são coincidentes com os espectros de emissão da maior parte das unidades de fotopolimerização por luz disponíveis, os LEDs azuis: Visando estabelecer um equilíbrio entre o grau de conversão das resinas e a concentração ideal de fotoiniciador, estudos como os de Musanje, Ferracane e Sakaguchi ${ }^{21}$ e Lima et al. 22 comprovaram que a elevação do teor de CQ resulta em melhores propriedades mecânicas, mas acima de um certo limiar, nenhum benefício a mais foi notado, pelo contrário, os autores sugerem que haja malefícios associados às altas concentrações, como lixiviação para saliva e tecidos ao redor, diminuindo a biocompatibilidade $^{21,22}$.

Maciel et al. $\stackrel{8}{ }$ desenvolveram análises utilizando resinas fluidas experimentais com o objetivo de avaliar o efeito da concentração de CQ nas propriedades físico-mecânicas destes materiais. Os compósitos foram preparados contendo concentrações diferentes de CQ $(0,25 \%, 0,50 \%, 1 \%, 1,5 \%$ e $2 \%)$ para serem avaliados quanto ao grau de conversão, dureza superficial, profundidade de polimerização, resistência à flexão e a outros aspectos. Ao comparar os grupos que continham as concentrações de 0,25\%,0,5\% e $1 \%$, constatou-se que houve um aumento significativo no grau de conversão e na resistência flexural, além da redução na taxa de amolecimento, sem haver variação quando a concentração foi aumentada para $1,5 \%$ e $2 \%$. O aumento da concentração de CQ em até $1 \%$ provocou também aumento do módulo de elasticidade quando comparada às demais concentrações. Portanto, percebe-se que o aumento da concentração de CQ até $1 \%$ resulta no aumento proporcional do grau de conversão e da maioria das propriedades mecânicas, mas acima deste limiar não há benefícios quanto aos aspectos avaliados. A única propriedade não afetada pela variação de concentração dos fotoiniciadores foi a dureza superficial e pode ser justificada pela polimerização adequada do material no topoㅛㅛ.

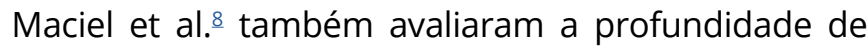
cura atingida entre as diversas concentrações de CQ. Em concentrações de 1\%, essa profundidade atingiu três milímetros, nas demais, apenas 2 milímetros. 0 que significa que o excesso de fotoiniciador resulta na atenuação da intensidade da luz ao longo do compósito. Maiores concentrações fazem com que apenas uma parte do fotoiniciador seja estimulada pela luz, já que ela encontra dificuldade de acessar camadas mais profundas do compósito, o que justifica a redução da profundidade de cura para compósitos contendo 1,5\% e $2 \%$ de concentrações de CQ ${ }^{10}$. Lima et al..$^{22}$ reforçam tal constatação quando explicam o efeito chamado de blindagem interna, e por isso, altas concentrações de CQ podem exercer papel de filtro que impede a luz de atingir porções mais profundas das restaurações. Tal mecanismo se torna um ciclo, pois se a luminosidade é baixa, menor é a profundidade de cura e menor a taxa de conversão dos monômeros, sendo assim, restarão espécies não reagidas no compósito22. Segundo Schneider, Cavalcante, Consani e Ferracane ${ }^{23}$ e Maciel et al., a presença dessas espécies é um dos fatores responsáveis por provocar a cor amarelada mais intensa nas resinas mal polimerizadas. Sendo assim, esse efeito limita a adição da CQ aos compósitos, já que altera o desfecho estético final 1,23 .

Outras substâncias fotoiniciadoras vem sendo testadas como forma de substituir ou minimizar os aspectos negativos apresentados pela CQ. Dentre os novos fotoiniciadores, pode-se destacar o 1-fenil-1;2-propanodiona (PPD), o óxido mono-acil fosfínico (TPO) e o óxido bisacilfosfínico (BAPO), fotoiniciadores do tipo I, os quais sofrem clivagem dos seus cromóforos durante a formação dos radicais livres sem a necessidade de associação com aminas terciárias e possuem tons mais claros, interferindo positivamente na cor final dos compósitos ${ }^{5}$.

Alvim ${ }^{5}$ investigou a reação de polimerização de um compósito experimental à base de BisGMA (14,5\% de massa a cada $100 \mathrm{~g}$ de compósito - $\mathrm{m} / \mathrm{m}$ ), Uretano Dimetacrilato (UDMA) $(6,5 \% \mathrm{~m} / \mathrm{m})$ e partículas de carga silanizadas $(79 \% \mathrm{~m} / \mathrm{m})$. O compósito foi dividido em quatro grupos e cada um recebeu um tipo de fotoiniciador, sendo eles: a CQ, o PPD, o TPO e o BAPO; estabelecendo uma comparação entre a reação de polimerização pela CQ e demais fotoiniciadores. 
O método eleito para realizar a investigação foi a fotocalorimetria por permitir acompanhar em tempo real a cinética da reação, com descrição da aceleração e grau de conversão final. Desta forma, o calor total liberado corresponde proporcionalmente ao número de monômeros convertidos e está relacionado à eficiência do sistema fotoiniciador. Após a realização dos testes, o BAPO foi o fotoiniciador que liberou mais calor e obteve maior velocidade $(44,93$ J/g), seguido do TPO (30,31 J/g). Apesar do PPD aparecer em seguida com nível inferior de liberação de calor, cerca de $27,92 \mathrm{~J} / \mathrm{g}$, a reação de polimerização ocorre de maneira mais lenta que todos os demais, e por isso, não acarreta prejuízos no grau de conversão final. A CQ apresentou os menores valores de calor liberado, cerca de $27,16 \mathrm{~J} / \mathrm{g}^{5}$.

Alguns autores $5,7,24$ desenvolveram estudos acerca das propriedades do PPD em comparação à CQ, e estabeleceram que o PPD possui faixa de absorção de comprimentos de ondas menor que a $C Q$, o que resulta na coloração da resina composta, menos amarelada, mesmo quando presente em altas concentrações. Apesar do seu pico de absorção estar entre 398 e $410 \mathrm{~nm}$, apresenta faixa útil na região da luz visível, o que possibilita a excitação do fotoiniciador sob irradiação da luz LED 5,724 . Ikemura e Endo ${ }^{24}$ relataram que o grau de conversão e a resistência mecânica do material que continha o PPD foram similares ou superiores aos compósitos que continham a CQ. Fato que está relacionado ao processo de polimerização das resinas compostas com esse sistema fotoiniciador, pois o mesmo acontece de forma mais lenta ${ }^{24}$. Segundo os autores ${ }^{24}$, a lentidão do processo consegue compensar o estresse gerado pela contração da resina composta nos momentos iniciais da reação. Ikemura e Endo ${ }^{24}$ e Alvim ${ }^{5}$ concordam ao dizerem que ao comparar o PPD e a CQ, utilizados sozinhos em sua forma pura, nenhuma diferença significativa foi detectada no grau de conversão. No entanto, quando analisados juntos, o efeito sinérgico da associação produziu resultados de grau de conversão mais elevados em relação aos apresentados por cada um individualmente ${ }^{5,24}$.

Assim como PPD, o BAPO também é um fotoiniciador do tipo I, possui absorção no espectro de luz visível na faixa de 365 a $416 \mathrm{~nm}$, além se apresentar em tons mais brancos que a CQ, característica que facilita a incidência da luz e aumenta sua reatividade ${ }^{5,22}$.
Porém, ao contrário das restaurações de resinas compostas com PPD e CQ incorporados, as que continham o TPO e o BAPO, apresentaram formação de gaps durante o processo de polimerização, pois tais substâncias possuem velocidade de reação de polimerização superior, e consequentemente, proporcionam para as resinas os piores índices de microinfiltração em dentina. Quando analisados em relação ao esmalte, restaurações com BAPO se comportaram de forma semelhante às de PPD e CQ, fornecendo à resina taxas satisfatórias de microinfiltração ${ }^{5}$.

Kim, Suh, Shin e Mahn ${ }^{19}$, Stansbury e Dickens ${ }^{25}$ e Goldberg ${ }^{26}$ relataram que resinas compostas à base de monômeros de dimetacrilato, como o Hidroxietil Metacrilato (HEMA), exibem ligações residuais de carbono $(\mathrm{C}=\mathrm{C})$ no produto final da polimerização e influenciam no grau de conversão, variando de $55 \%$ a $75 \%$, resultando em baixa resistência mecânica $a^{19,25,26}$. Como forma de tentar contornar o prejuízo mecânico, os autores ${ }^{19}$ utilizaram um compósito de Bis-GMA (60\%) e HEMA (40\%), variando os co-iniciadores. As amostras foram divididas em 5 grupos: (1) CQ associada ao 2-dimetilaminoetilo metacrilato (DMAEMA); (2) CQ associada 4-dimetilamino benzoato de etila (EDMAB); (3) CQ ao hexafluorofosfato de difeniliodônio (DPIHFP), não houve adição de amina terciária; (4) CQ associada ao DMAEMA e DPIHFP; e (5) CQ associada ao EDMAB e DPIHFP. Os autores avaliaram o grau de conversão em tempo real através de espectrômetro, a microdureza e a resistência flexural. Em todos os testes, o grupo 3 mostrou valores inferiores aos demais, sendo justificado pelo autor pela falta da amina terciária e formação insuficiente de radicais livres, o que pode ter acarretado na polimerização inadequada do compósito. Os autores observaram que os grupos 2, 4 e 5 tiveram praticamente o mesmo grau de conversão, com valores médios de $64,55 \%, 64,56 \%$ e $65,32 \%$, respectivamente. Enquanto o grupo 3, que não possuía amina terciária, apresentou valor significativamente menor (55,58\%). Os grupos 4 e 5, com sistemas iniciadores ternários, apresentaram resistência à flexão semelhantes; entretanto, a microdureza no grupo 5 foi superior, característica atribuída ao EDMAB. Por fim, o estudo concluiu que os sistemas com sais de iodônio (DPIHFP) como terceiro fator, podem resultar em maior grau de conversão e propriedades mecânicas melhoradas, desde que associados aos co-iniciadores à base de amina ${ }^{19}$. 
Os materiais ativados por meio de luz são diversos, assim como as resinas compostas, os cimentos com matriz resinosa também passam por esse processo de polimerização. Lima et al..22 investigaram a influência de diferentes concentrações de inciadores como CQ e BAPO junto com o co-iniciador metacrilato de dimetilaminoetil (DMAEMA) na resistência à flexão e módulo de elasticidade de cimentos resinosos. As amostras foram divididas de acordo com o co-iniciador em dois grupos (CQ e BAPO), subdivididos de acordo com diferentes concentrações do iniciador e co-iniciador: CQ $(0,1 \%, 0,3 \%, 0,5 \%$ e $0,7 \%)$ e DMAEMA (0\% e $0,5 \%)$; BAPO $(0,2 \%, 0,7 \%, 1,2 \%$ e $1,7 \%)$ e DMAEMA ( $0 \%$ e $0,5 \%$ ). Como era esperado, os grupos de CQ que continham $0 \%$ de DMAEMA não polimerizaram, fornecendo valores inferiores de resistência à flexão e módulo de elasticidade. Enquanto as amostras do grupo com BAPO polimerizaram, mas não obtiveram diferenças significativas entre si quanto à resistência à flexão, independente da variação de concentração. Todavia, os autores constataram que nos grupos de resina composta que continham BAPO, os valores de resistência flexural e módulo de elasticidade foram maiores em relação aos que continham CQ e justificaram a partir da característica de alto rendimento quântico do BAPO, que chega a ser cinco vezes maior do que a do CQ. Quanto maior esse rendimento, menor a quantidade de energia necessária para realizar a reação de polimerização do compósito 22 .

Almeida et al. $\stackrel{9}{ }$ avaliaram o grau de conversão e a citotoxicidade com relação a concentração de CQ e diferentes substâncias fotoiniciadoras (CQ, BAPO, TPO e TBA) e co-iniciadoras (EDAB, AP, BDO, DPIHFP) em adesivos autocondicionantes. Em relação à $C Q$, ao AP e ao TBA foi visto que eles apresentam efeito citotóxico elevado quando encontrados em concentrações acima de $25 \mathrm{MM}$ (massa molar), mas ainda não se conhece o mecanismo de ação da toxicidade da CQ, foi constatado apenas que é um efeito dose dependente. Segundo o autor, CQ atingiu o maior nível de citotoxidade quando foi associada aos co-iniciadores AP e BDO. porém, quando os co-iniciadores foram avaliados de forma isolada, não demonstraram citotoxidade, o que sinaliza que a difusão da CQ pode ter provocado a citotoxicidade. Outro fator importante que está associado aos danos causados às células, é que o sistema CQ + AP apresentou índice muito baixo de grau de conversão, o que significa que monômeros residuais podem ter provocado a toxicidade observada, além de também poderem exercer influência negativa no desempenho mecânico.
Ainda no estudo de Almeida et al. $\stackrel{9}{ }$, detectou-se que a CQ + TBA apresentou maior viabilidade celular, além de ter melhorado a reatividade e o grau de conversão, o que torna o TBA uma alternativa satisfatória quanto aos demais co-iniciadores, já que é de extrema importância a criação e desenvolvimento de materiais resinosos mais biocompatíveis e com melhor grau de conversão?

Neste sentido, o grande desafio dos estudos mais recentes é estabelecer a concentração e o tipo ideal das substâncias fotoiniciadoras nas resinas compostas, levando em consideração a composição da sua matriz e a interação das subtâncias iniciadoras com a mesma, com o objetivo de reduzir os efeitos citotóxicos e de pouca biocompatibilidade que os fotoiniciadores em excesso fornecem. Assim, estabelecer a concentração mínima ideal responsável por fornecer vantagens como: redução do estresse de contração e favorecer a integridade interfacial das restaurações, mas mantendo a polimerização eficaz, sem apresentar defeitos e sem interferir negativamente nas propriedades mecânicas e na estabilidade química do material. Porém, para ajustar a concentração ideal dessas substâncias, se faz necessário levar em consideração também a os tipos de monômeros presentes na matriz resinosa e dessa forma, elevar o nível de eficácia da reação de polimerização

\section{Aparelhos fotoativadores: características e interferências clínicas}

Os fotoiniciadores alternativos à CQ, absorvem luz nos comprimentos de onda menor que $410 \mathrm{~nm}$ e são menos sensíveis à luz na faixa de 450 a 468 nm, luz emitida pelas unidades de LED ${ }^{27}$. Nesse ponto tinhase uma inconsistência, pois a evolução das substâncias iniciadoras acabou não acompanhando a tecnologia dos aparelhos emissores de luz. Além disso, as lâmpadas LED de segunda geração emitem pico único de luz e não eram muito eficazes, devido à pouca quantidade de luz com comprimento abaixo de 410 $\mathrm{nm}$. Como forma de solucionar tais problemas, surgiram no mercado os LED's de terceira geração, também chamados de Polywaves, aparelhos de LED que emitem espectro de onda maior e atinge também a cor violeta, necessária para ativar a reação química de polimerização dos fotoiniciadores alternativos. Então, ao incorporar vários emissores de cores nas luzes de LED, a faixa espectral necessária para fotoativar os fotoiniciadores alternativos passa a ser entregues aos materiais restauradores 28,29 . 
Falando no impacto da fotoativação e suas variáveis no desempenho mecânico das resinas compostas, é possível perceber que esta é uma etapa comumente subestimada nos procedimentos restauradores realizados tanto em consultórios como nas instituições de ensino $18,20,30$. Portanto, para iniciar a discussão acerca da fotoativação, é preciso pontuar alguns conceitos. O primeiro deles, a irradiância (dada em unidades de $\mathrm{mw} / \mathrm{cm} 2$ ), que é característica do aparelho fotoativador dada pelo fabricante, determinada pela divisão da potência pela área da ponta ativa do aparelho ${ }^{30}$. Chamada de densidade de potência por Beolchi et al. $\stackrel{11}{ }$, os autores definiram a irradiância como a quantidade de luz recebida pelo compósito em uma determinada área ${ }^{11}$. O segundo conceito é a energia que realmente parte do equipamento, chamada de radiância emitida ${ }^{30}$. O terceiro é quantidade de energia recebida pela superfície do compósito, chamada de energia radiante, dada em Joules $(\mathrm{J})^{11,30}$.

A obtenção de um elevado grau de conversão constitui uma das principais preocupações quanto ao processo de fotopolimerização das resinas compostas e segundo Beolchi et al. $\stackrel{11}{ }$, é uma das condições para o sucesso à longo prazo das restaurações ${ }^{11}$. Para o compósito atingir um nível satisfatório de cura, ele deve ser exposto a uma fonte de luz azul por um determinado tempo. Autores como Beolchi et al. ${ }^{11}$ e Shortall, Price, Mackenzie e Burke ${ }^{30}$ afirmam que atualmente, a partir de evidência científica, não existe determinado o valor exato da energia necessária para polimerizar completamente um compósito, pois esse aspecto vai variar de acordo com o tipo de cor, espessura do incremento, translucidez e tipo de fotoiniciador contido em cada resina, assim como depende também do desempenho do aparelho utilizado, da técnica e de aspectos comportamentais do operador. Mas, outros autores, 10,11,31-33 afirmam que a dose mínima necessária para polimerizar completamente um compósito de 2 milímetros ( $\mathrm{mm}$ ) e atingir as propriedades mecânicas ideais dele é de 16 Joules por centímetros quadrados $(\mathrm{J} / \mathrm{cm} 2)$. Shortall, Price, Mackenzie e Burke ${ }^{30}$ afirmam que determinar a quantidade de energia exata para polimerizar um compósito é um aspecto bastante subjetivo, pois, com a variedade de resinas compostas disponíveis no mercado, é comum que hajam variações no comportamento de cada uma delas. Enquanto um incremento pode ser polimerizado numa profundidade maior em mais tempo, outra pode polimerizar mais rápido ${ }^{30}$.
Alguns autores ${ }^{11,18,29}$ encontraram fatores que influenciam diretamente na irradiância e na energia radiante provenientes das unidades de fotoativação, e consequentemente interferem também na integridade das restaurações, na longevidade, na biocompatibilidade e no desempenho mecânico ${ }^{11,18,29}$. Tais fatores são: o tempo de fotoativação, a distância entre a fonte de luz e a cavidade a ser restaurada, a colimação do feixe de luz, a homogeneidade do facho de luz e o correto posicionamento e direcionamento da unidade fotoativadora ${ }^{11,18,29}$.

Sobre a influência do tempo, ele está diretamente ligado com a exposição radiante (densidade de potência multiplicada pelo tempo), que é o principal fator determinante do grau de conversão e das propriedades mecânicas do material ${ }^{34}$. Em relação a esse tempo de exposição do material restaurador à luz, é preciso salientar que a maioria dos fabricantes recomendam nas instruções de uso um tempo padrão de polimerização, sem levar em conta os diversos fatores que estão diretamente ligados à essa etapa, por conta disso, alguns autores classificam os cálculos de tempo baseados apenas na radiação total como inválidos $28,30,35$. Beolchi et al. ${ }^{11}$ desenvolveram um estudo comparativo entre quatro dispositivos de luz diferentes, sendo três emissores de luz de LED (Elipar Freelight 2 (3M ESPE, São Paulo, EUA); Radi-cal (SDI Limited, Victoria, Austrália) e Valo (Ultradent Produtos, South Jordan, EUA) e um emissor de luz halógena (Optilux 401, Demetron/Kerr, Danbury, EUA). Os autores posicionaram tais dispositivos a diferentes distâncias: $0 \mathrm{~mm}$, $4 \mathrm{~mm}$ e $8 \mathrm{~mm}$ com o objetivo de analisar a influência da distância na quantidade de tempo necessária para atingir o valor de $16 \mathrm{~J} / \mathrm{cm} 2$ de densidade de energia, necessária para excitar as substâncias fotoiniciadoras e realizar a reação de polimerização do material. Para a aplicação dos testes, todas as lâmpadas foram conectadas a um dispositivo, responsável pela estabilização da lâmpada de cura e pelo controle da distância da ponta ao sensor receptor de luz. Esse sensor foi utilizado como simulador do compósito em relação à localização e usado também para detectar a energia recebida. Ao concluir os testes, os autores perceberam que quando a distância entre a ponta e o sensor receptor da luz aumentou, o tempo para atingir $16 \mathrm{~J} / \mathrm{cm} 2$ também aumentou. $O$ dispositivo de lâmpada de halogênio precisou do tempo mais longo entre todos os avaliados, cerca de 94,96 segundos, enquanto o mínimo de tempo foi alcançado pelo Valo com o tempo de 13,03 segundos em média ${ }^{11}$. 
A distância entre a fonte de luz e a superfície da resina composta é também extremamente importante, principalmente quando se trata de restaurações em dentes posteriores, mais especificamente, as cavidades de classe II. Em cavidades profundas e/ou com paredes remanescentes altas, e com anéis e matrizes, estes fatores impõem dificuldades para a estabilização, aproximação e melhor posicionamento da fonte de luz, aumentando ainda mais a distância e prejudicando o processo de fotoativação. Autores relatam que a fotoativação lateral adicional nas restaurações de classe II é uma maneira eficaz de obter uma polimerização adequada da resina ${ }^{30,35}$.

A distância está atrelada também ao grau de colimação do feixe luminoso, ou seja, a capacidade do aparelho em aumentar a quantidade de luz que estará encerrada dentro da cavidade e minimizar a dispersão dela, pois essa perda diminui a quantidade de energia recebida pela restauração e o compósito acaba não sendo curado adequadamente. Portanto, à medida que essa distância aumenta, se o grau de colimação não for satisfatório, maior será a perda de energia e maior o risco de subpolimerizar o material $11,18,30,35$.

Reforçando a constatação anterior, Shortall, Price, Mackenzie e Burke ${ }^{30}$ alertaram que a distância entre a fonte de luz e o compósito realmente influencia no nível de cura ou polimerização: "valor de irradiância da unidade de cura da luz indicado pelo fabricante raramente é alcançado quando a unidade está posicionada a uma distância clinicamente relevante de 4 mm ou mais da resina" ${ }^{\prime 30}$. Ou seja, nas cavidades de Classe II em que a parede pulpar está há uma distância maior que $4 \mathrm{~mm}$, podendo atingir $8 \mathrm{~mm}$ de profundidade em situações extremas, naturalmente, já há uma significativa perda de energia e maior risco de não atingir o incremento mais profundo da restauração, deixando-o mal polimerizado 11,18,27,28, 30 .

Num estudo realizado com luzes de naturezas diferentes e com variação da distância de fotoativação, foi detectado que todos os dispositivos demandaram de maior tempo para atingir uma energia fornecida de $16 \mathrm{~J} / \mathrm{cm} 2$ à medida em que se aumentava a distância entre a fonte de luz e a restauração. Em contrapartida, restaurações em dentes anteriores tem esse problema minimizado, já que essa distância é quase inexistente ${ }^{11}$. Outros autores ${ }^{10,36,37}$ também avaliaram a quantidade de energia recebida por materiais polimerizados à uma distância maior que $4 \mathrm{~mm}$, podendo chegar até $8 \mathrm{~mm}$, e constataram que com o tempo determinado por alguns fabricantes, a camada mais profunda de um compósito chega a receber $2 \mathrm{~J} / \mathrm{cm} 2$ de energia, ou seja, nível muito aquém do estabelecido como energia ideal para polimerizar adequadamente um incremento de resina composta, que é $16 \mathrm{~J} / \mathrm{cm} 2$ 10,36,37.

Outro aspecto abordado por estudos sobre os apareIhos fotoativadores é a homogeneidade do facho de luz, ou seja, a forma com que a luz chega ao compósito. Ela precisa chegar ao material de forma homogênea, sem picos de potência em determinadas regiões e diminuição dessa potência em outras. Essa variação pode significar uma polimerização não uniforme ao longo do compósito e fornecer restaurações com material subpolimerizado, que superficialmente encontra-se endurecido, mas não totalmente polimerizado no seu interior $11,20,28$.

Considerando a interferência do correto posicionamento e direcionamento da unidade fotoativadora, é possível perceber que esse é um fator dependente do aspecto comportamental do operador, já que a técnica aplicada afetará diretamente a quantidade de energia entregue ao material, por isso, faz-se necessária uma preparação padrão dos responsáveis pela etapa de polimerização e a proteção ocular apropriada, para que ele possa assistir com atenção o que está sendo feito. Quanto ao direcionamento da ponta ativadora, a luz deve estar posicionada diretamente sobre a restauração, minimizando a cobertura de tecidos moles e evitando sombras. A fotoativação lateral após a remoção de bandas e matrizes é uma maneira eficaz de completar a cura da superfície oclusal 20,228 .

A opacidade, a cor, a composição, o tamanho das partículas de preenchimento da resina e a incompatibilidade do índice de refração também afetam a determinação do tempo ideal para polimerizar cada compósito e refletirá também na profundidade da cura do materia 130,35 . Além da qualidade, natureza da luz e irradiância do aparelho fotoativador, é importante ter o controle do tempo por conta do aumento de temperatura que a energia emitida por ele provoca, aumentando as chances de aquecimento excessivo dos dentes, de danos ao tecido pulpar e de queima dos tecidos moles 28,30 . 
Todos os fatores e aspectos abordados tem sua parcela de influência na quantidade de energia emitida pelo dispositivo fotoativador e recebida pelo material a ser polimerizado. $O$ fornecimento de pouca energia luminosa pode ser responsável por falhas precoces, cáries secundárias, fraturas e pelo comprometimento das propriedades mecânicas e físicas do material restaurador 11,18,28.

\section{Considerações finais}

A partir da revisão da literatura apresentada, foi possível concluir que a CQ ainda é a substância mais usada nos sistemas fotoiniciadores e que tem sido necessário estabelecer uma concentração ideal desse fotoiniciador, para que as melhores propriedades físicas e mecânicas sejam atingidas, sem comprometer o aspecto estético. Seguindo essa linha, estudos recentes comprovaram que a concentração em torno de $1 \%$ confere maior grau de conversão e maior resistência flexural. Em relação aos fotoiniciadores alternativos à canforoquinona, o PPD apresenta bom desempenho físico-mecânico e químico, detectado a partir da avaliação do grau de conversão e da resistência flexural. As demais substâncias fotoiniciadoras também apresentaram bons resultados, porém, alguns apresentaram aspectos desfavoráveis como alta toxicidade acima de concentrações ideais, enquanto outros provocaram na resina composta a formação de gaps durante o processo de polimerização devido à velocidade de reação e por conta disso, geraram também os piores índices de microinfiltração em dentina.

A correlação entre os fotoiniciadores alternativos e as fontes de luz configuravam uma incompatibilidade na Odontologia, mas com a criação das luzes de LED de terceira geração, os aparelhos polywaves, o fornecimento de luz passa a oferecer a quantidade de energia necessária para polimerizar as resinas compostas com novas substâncias fotoiniciadoras, assim como possuem alta irradiância e alto grau de colimação do feixe, resultando em propriedades físicas e mecânicas satisfatórias. Além disso, foi possível detectar que o tempo de ativação especificado pelos fabricantes é insuficiente para fornecer $16 \mathrm{~J} / \mathrm{cm} 2$ nos casos em que a distância entre a fonte de luz e a restauração é aumentada ou quando a potência do aparelho varia.
Ao polimerizar a resina composta deve-se conhecer a composição do material, as substâncias fotoiniciadoras empregadas nas resinas compostas e suas concentrações, a fonte de luz empregada, o espectro luminoso, a potência do aparelho e levar em consideração os aspectos comportamentais do operador. Dessa forma, para que o cirurgião dentista realize procedimentos restauradores satisfatórios quanto ao desempenho clínico, é preciso que os fabricantes disponibilizem as informações necessárias para que o profissional conheça o material e o aparelho que está trabalhando, para que não negligencie a etapa da fotoativação.

\section{Contribuições das autoras}

Boaventura RS participou das buscas das referências utilizadas para confecção do artigo científico, assim como a elaboração da metodologia, construção da revisão de literatura e redação do artigo. Basílio MA participou da orientação para a construção do artigo científico e realizou as correções do mesmo.

\section{Conflitos de interesses}

Nenhum conflito financeiro, legal ou político envolvendo terceiros (governo, empresas e fundações privadas, etc.) foi declarado para nenhum aspecto do trabalho submetido (incluindo, mas não se limitando a subvenções e financiamentos, participação em conselho consultivo, desenho de estudo, preparação de manuscrito, análise estatística, etc.).

\section{Referências}

1. Mallmann A, Jesus SS, Teixeira Neto A, Fontes CM, Jacques LB. Resistência flexural de resinas compostas imersas em diferentes líquidos. Robrac [Internet]. 2009;18(45):11-6. Disponível em: https://www.robrac.org.br/seer/index.php/ROBRAC/article/ view/30/20

2. Bispo LB. Resina composta nanoparticulada: há superioridade no seu emprego?. Rev dent on line [Internet]. 2010;9(19):21-4. Disponível em: http://coral.ufsm.br/dentisticaonline/0904.pdf

3. Fares NH, Nagem H, Pacheco IB, Coutinho KQ, Nagem HD. Resistência flexural e módulo de elasticidade da resina composta. Rev de Clín Pesq Odontol [Internet]. 2005;2(1):53-5. Disponível em: https://periodicos.pucpr.br/index.php/oralresearch/ article/download/22855/21959\#: : :text=\%C3\%89\%200\%20 princ\%C3\%ADpio\%20de $\% 20$ quanto,0\%20endurecimento $\% 20$ da\%20resina\%20composta 
4. Baratieri LN, Monteiro Jr S, Melo TS, Ferreira KB, Hilgert LA, Schlichting LH, et al. Polimerização de compósitos. In: Baratieri LN, Monteiro Jr S, Melo TS, Ferreira KB, Hilgert LA, Schlichting LH, et al. Odontologia Restauradora: fundamentos \& técnicas. São Paulo: Santos; 2013. p. 121-33.

5. Alvim HH. Estudo dos fotoiniciadores utilizados em resinas compostas. [dissertação] [Internet]. Araraquara: Universidade Estadual de São Paulo; 2008. Disponível em: https://repositorio. unesp.br/handle/11449/101380

6. Carvalho KA. Influência de diferentes tipos de fotopolimerizadores e fotoiniciadores na rugosidade e brilho de resinas compostas, frente a diferentes desafios. [monografia] [Internet]. Araçatuba: Universidade Estadual de São Paulo; 2016. Disponível em: https://repositorio.unesp.br/handle/11449/155317

7. Porto ICCM. Influência da interação entre fotoiniciadores e fontes de energia sobre o grau de conversão de resinas compostas. [dissertação] [Internet]. Taubaté: Universidade de Taubaté; 2006. Disponível em: http://www.dominiopublico.gov.br/ pesquisa/DetalheObraForm.do? select action $=\&$ co obra $=28486$

8. Maciel DDSA, Caires-Filho AB, Fernandez-Garcia M, AnauateNetto C, Alonso RCB. Effect of Camphorquinone Concentration in Physical-Mechanical Properties of Experimental Flowable Resin Composites. Biomed Res Int. 2018;2018:7921247. https://dx.doi. org/10.1155\%2F2018\%2F7921247

9. Almeida SM, Meereis CTW, Leal FB, Carvalho RV, Boeira PO, Chisini LA et al. Evaluation of alternative photoinitiator systems in two-step self-etch adhesive systems. Dent Mater. 2020;36(2):2937. https://doi.org/10.1016/j.dental.2019.11.008

10. Benetti AR, Asmussen $E$, Peutzfeldt A. Influence of curing rate of resin composite on the bond strength to dentin. Oper Dent. 2007;32(2):144-8. https://doi.org/10.2341/06-39

11. Beolchi RS, Moura-Netto C, Palo RM, Torres CRG, Pelissier B. Changes in irradiance and energy density in relation to different curing distances. Braz Oral Res. 2015;29(1):1-7. https://doi. org/10.1590/1807-3107bor-2015.vol29.0060

12. Schneider AC, Mendonça MJ, Rodrigues RB, Busato PMR, Camilotti V. Influência de três modos de fotopolimerização sobre a microdureza de três resinas compostas. Polímeros. 2016;26(spe):37-42. https://doi.org/10.1590/0104-1428.1855

13. Souza ROA, Michida SMA, Zogheib LV, Lombardo GHL, Pereira PC, Barca DC, et al. Avaliação da dureza Vickers de resinas compostas de uso direto e indireto. Cienc Odontol Bras [Internet]. 2009;12(1):23-30. Disponível em: https://bds.ict.unesp.br/index. php/cob/article/view/249/189

14. Souza-Júnior E, Hernández CP, Brandt WC, Sinhoreti MAC. Fotoativação na Atualidade: Conceitos e Técnicas. Clín nt J Braz Dent [Internet]. 2014;10(2): 194-203. Disponível em: https:// www.researchgate.net/publication/275522509 Fotoativacao na atualidade_Conceitos_e_tecnicas_clinicas\#read
15. Rueggeberg FA. State of the art: dental producing - a review. Dent Mater J. 2011;27(1):39-52. https://doi.org/10.1016/j. dental.2010.10.021

16. Bowen RL. Dental filling material comprising vinyl-silane treated fused silica and a binder consisting of the reaction product of bisphenol and glycidil methacrylate. U. S. Patent; 3,066,112, 1962.

17. Fúcio SBP, Carvalho FG, Sobrinho LC, Sinhoreti MAC, PuppinRontani RM. The influence of 30 day old streptococcus mutans biofilme on the surface of esthetic restorative materials an in vitro study. J Dent. 2008;36(10):833-9. https://doi.org/10.1016/j. jdent.2008.06.002

18. Beolchi RS, Forti W, Garófalo JC, Palo RM. O seu fotopolimerizador está preparado para os novos materiais?. Rev Assoc Paul Cir Dent. 2013;01(2):186-96. http://www.apcd.org.br/ revistaestetica/03 mat destaque1.html

19. Ki Kim M, Suh BI, Shin D, Kim KM. Comparison of the Physical and Mechanical Properties of Resin Matrix with Two Photoinitiator Systems in Dental Adhesives. Polymers (Basel). 2016;8(7):250. https://doi.org/10.3390/polym8070250

20. Price RB, Shortall AC. Essentials of light curing. Dent Update. 2018;45(5):400-6. https://doi.org/10.12968/denu.2018.45.5.400

21. Musanje L, Ferracane JL, Sakaguchi RL. Determination of the optimal photoinitiator concentration in dental composites based on essential material properties. Dent Mater J. 2009;25(8):9941000. https://doi.org/10.1016/j.dental.2009.02.010

22. Lima CR, Silva DB, Vitti RP, Miranda ME, Brandt WC. Mechanical properties of experimental resin cements containing different photoinitiators and co-initiators. Clin Comet Investig Dent. 2019;11:285-90. https://dx.doi.org/10.2147\%2FCCIDE. $\mathrm{S} 221742$

23. Schneider LFJ, Cavalcante LM, Consani S, Ferracane JL. Effect of co-initiator ratio on the polymer properties of experimental resin composites formulated with camphorquinone and phenylpropanedione. Dent Mater J. 2009;25(3):369-75. https://doi. org/10.1016/j.dental.2008.08.003

24. Ikemura K, Endo T. A review of the development of radical photopolymerization initiators used for designing lightcuring dental adhesives and resin composites. Dent Mater J. 2010;29(5):481-501. https://doi.org/10.4012/dmj.2009-137

25. Stansbury JW, Dickens SH. Determination of double bond conversion in dental resins by near infrared spectroscopy. Dent Mater J. 2001;17(1):71-9. https://doi.org/10.1016/S01095641(00)00062-2

26. Goldberg M. In vitro and in vivo studies on the toxicity of dental resin components: a review. Clin Oral Invest. 2008;12(1):18. https://doi.org/10.1007/s00784-007-0162-8 
27. Price RBT, Fahey J, Felix CM. Knoop Microhardness Mapping Used to Compare the Efficacy of LED, QTH and PAC Curing Lights. Oper Dent. 2010;35(1):58-68. https://doi.org/10.2341/09-055-I

28. Price RB, Shortall AC, Palin WM. Contemporary issues in light curing. Oper Dent. 2014;39(1):4-14. https://doi.org/10.2341/13067-lit

29. Price RBT. Light Curing in Dentistry. Dent Clin North Am. 2017;61(4):751-78. https://doi.org/10.1016/j.cden.2017.06.008

30. Shortall AC, Price RB, Mackenzie L, Burke FJT. Guidelines for the selection, use, and maintenance of LED light-curing units Part 1. Br Dent J. 2016;221(8):453-60. https://doi.org/10.1038/ sj.bdj.2016.772

31. Peutzfeldt A, Asmussen E. Resin composite properties and energy density of light cure. J Dent Res. 2005;84(7):659-62. https:// doi.org/10.1177/154405910508400715

32. Gritsh K, Souvannasot S, Schembri C, Farge P, Grosgogeat B. Influence of light energy and power density on the microhardness of two nanohybrid composites. Eur J Oral Sci. 2008;116(1):77-82. https://doi.org/10.1111/j.1600-0722.2007.00506.x
33. Bortolotto T, Dagon C, Krejci I. Light polymerization during cavity filling: Effect of 'exposure reciprocity law' and the resulted shrinkage forces on restoration margins. Acta Odontol Scand. 2013;71(5):1296-302. Citado em: PMID: 23796309

34. Leprince JG, Hadis M, Shortall AC, Ferracane JL, Devaux J, Leloup $\mathrm{G}$, et al. Photoinitiator type and applicability of exposure reciprocity law in filled and unfilled photoactive resins. Dent Mater J. 2011;27(2):157-64. https://doi.org/10.1016/j.dental.2010.09.011

35. Jong LCG, Opdam NJM, Bronkhorst EM, Roeters JJM, Wolke JGC, Geitenbeek B. The effectiveness of different polymerization protocols for class II composite resin restorations. J Dent. [Internet]. 2007;35(6): 513-20. https://pubmed.ncbi.nlm.nih. gov/17383067/

36. Lovell LG, Newman SM, Donaldson MM, Bowman CN. The Effect of light intensity on double bond conversion and flexural strength of a model, unfilled dental resin. Dent Mater J. 2003;19(6):458-65. https://doi.org/10.1016/s0109-5641(02)00090-8

37. Calheiros FC, Daronch M, Rueggeberg FA, Braga R. Degree of conversion and mechanical properties of a BisGMA: TEGDMA composite as a function of the applied radiant exposure. J Biomed Mater Res B Appl Biomater. 2007;84(2):503-9. https://doi. org/10.1002/jbm.b.30897 